SARA MARIA ZAGO GOMES

\title{
EXPRESSÃO E ATIVIDADE DA NAD(P)H-OXIDASE DE MEMBRANA NAS CÉLULAS TROFOBLÁSTICAS DE CAMUNDONGO
}

TESE APRESENTADA AO INSTITUTO DE CIÊNCIAS BOMÉDICAS DA UNIVERSIDADE DE SÃO PAULO, PARA A OBTENÇÃO DO TÍTULO DE DOUTOR EM CIÊNCIAS.

ÁREA DE CONCENTRAÇÃO: BIOLOGIA CELULAR E TECIDUAL ORIENTADORA: PROF $^{\text {a }}$ DR $^{\text {a }}$ ESTELA BEVILACQUA

\section{SÃO PAULO}




\section{EXPRESSÃO E ATIVIDADE DA NAD(P)H-OXIDASE DE MEMBRANA NAS CÉLULAS TROFOBLÁSTICAS DE CAMUNDONGO}

\section{RESUMO}

GOMES, S.M.Z. Expressão e atividade da NAD(P)H-oxidase de membrana nas células trofoblásticas de camundongo. 2008. 77 f. Tese (Doutorado em Biologia Celular e Tecidual) - Instituto de Ciências Biomédicas, Universidade de São Paulo, São Paulo, 2008.

Em macrófagos e neutrófilos, a ativação da fagocitose é definida pela aquisição de competência para o desempenho de funções tumoricidas, microbicidas ou citolíticas resultantes da produção e liberação de espécies reativas de oxigênio, além do processo de fagocitose propriamente dito. Como estes fagócitos, as células trofoblásticas em muitas espécies também são fagocitárias. Esta população celular envolve completamente o embrião e expressa diferentes e específicas características durante a gestação. Em roedores e primatas, estas células estrategicamente posicionadas entre a circulação materna e fetal., exibem atividade fagocitária e invasiva, são responsáveis pela ancoragem do embrião no endométrio e pelo provimento de um adequado suprimento nutricional para o desenvolvimento embrionário. Em roedores, estas atividades apresentam um grau máximo durante o período de implantação, declinando gradativamente, à medida que a placenta se desenvolve. Na presença de partículas estranhas na interface materno-placentária, no entanto, este processo pode ser reativado e, neste caso, possivelmente relacionado à mecanismos de defesa. Estudos anteriores realizados em nosso laboratório mostraram a capacidade destas células em produzir e liberar espécies reativas de oxigênio/nitrogênio, de uma maneira muito semelhante ao observado em fagócitos. A produção destas moléculas está geralmente associada à atividade de inúmeras enzimas, mas a localização de sítios de produção de peróxido de hidrogênio na superfície do trofoblasto sugeriu atividade $\mathrm{NAD}(\mathrm{P}) \mathrm{H}$-oxidase. Esta enzima é formada por um citocromo b558 associado à membrana celular (subunidades p22-phox e gp91-phox) e as subunidades citosólicas p47-phox, p67phox, p40-phox e GTPases Rac1 e Rac2 em um sistema gerador de elétrons que utiliza como substrato a NADH ou NADPH, dependendo da célula considerada. Uma vez ativado, o complexo enzimático é responsável pelo influxo de elétrons que com o oxigênio 
molecular forma ânions superóxidos. Assim, baseando-nos na literatura e resultados prévios obtidos por nosso grupo, este estudo analisou a expressão protéica e gênica das subunidades do complexo $\mathrm{NAD}(\mathrm{P}) \mathrm{H}$-oxidase em células trofoblásticas de camundongo, respectivamente através de localização imunohistoquímica e Western-blotting e RT-PCR, sob o estímulo com PMA. As análises semi-quantitativas em rt-PCR mostraram uma expressão gênica aumentada das subunidades p22-phox, gp91-phox, p47-phox, p67-phox, p40-phox e GTPase Rac1 nas células trofoblásticas das amostras tratadas com PMA em relação às não tratadas. A presença das subunidades p47-phox, p67-phox e gp91-phox também foi confirmada por Western Blotting e obedeceu ao mesmo padrão da expressão gênica, ou seja, aumento na presença de PMA. Estas subunidades foram imunolocalizadas principalmente nas células trofoblásticas gigantes, associadas a processos fagocíticos na interface materno-placentária. O aumento na expressão destas subunidades indica um aumento na disponibilidade de $\mathrm{NAD}(\mathrm{P}) \mathrm{H}$-oxidase, o que pode estar relacionado a um aumento na atividade desta enzima. Para avaliar esta possibilidade e determinar o papel da NAD(P)H-oxidase na produção total de espécies reativas de oxigênio pelo trofoblasto ensaios celulares foram realizados utilizando a fluorescência do oxietídio, um produto gerado pela oxidação do DHE pelo ânion superóxido. Utilizando-se PMA e bloqueadores específicos da atividade enzimática $\mathrm{NAD}(\mathrm{P}) \mathrm{H}$-oxidase de membrana (apocinina), mitocondrial (antimicina) e da enzima xantina oxidase (alopurinol) e sequestradores específicos do ânion superóxido (superóxido dismutase) e do peróxido de hidrogênio (catalase) foi possível mostrar a produção destas espécies reativas de oxigênio pelas células trofoblásticas, principalmente quando estimuladas e a partir da atividade NAD(P)Hoxidase. Estes resultados vêm acrescentar informações importantes sobre o potencial das células trofoblásticas em produzir espécies reativas na interface materno-fetal e abre uma nova linha de investigação dos processos de regulação desta enzima e seu envolvimento em funções de defesa e proteção do organismo embrionário/fetal ou em processos patológicos que podem determinar o insucesso da gestação.

Palavras-Chave: Células trofoblásticas; fagocitose; NAD(P)H-oxidase; ânion superóxido; gp91-phox; p67-phox. 


\begin{abstract}
\end{abstract}
GOMES, S. M. Z. Expression and activity of the membrane NAD(P)H-oxidase in the mouse trophoblast cells. 2008. 77 f. Tese (Doutorado em Biologia Celular e Tecidual) Instituto de Ciências Biomédicas, Universidade de São Paulo, São Paulo, 2008.

In macrophages and neutrophils, the activation of the phagocytosis is defined by the acquisition of competence for microbicide, tumoricide and cytolytic functions resultant of generation and release of oxygen reactive species, besides the phagocytic process per se. Like these phagocytes, trophoblast cells in many species are also phagocytic. This cellular population involves completely the embryo and exhibits different and specific characteristics along the gestation. In rodents and primates, these cells are strategically positioned between maternal and fetal circulation and exhibit invasive and phagocytic activity, respectively responsible for anchorage of the embryo into the endometrium and uptake of an adequate nutritional supply for the embryo development. In rodents, these activities present a maximum degree during the implantation period, gradually declining, as the placenta develops. In the presence of strange particles at the maternal-placental interface, however, this process can be reactivated and, in this case, may be related to defense's mechanisms. Previous studies performed in our laboratory showed the potential of the trophoblast in producing and releasing reactive species of oxygen/nitrogen, in a very similar manner to that observed in macrophages and neutrophils. The production of such molecules is associated to different enzymes, but the localization of hydrogen peroxide on trophoblast cell surface has suggested a NAD $(\mathrm{P}) \mathrm{H}$-oxidase activity. NAD $(\mathrm{P}) \mathrm{H}$-oxidase is formed by the cytochrome $\mathrm{b}_{558}$ associated to the cellular membrane (subunits p22-phox + gp91-phox), the cytosolic subunits p47-phox, p67-phox and p40-phox and, the GTPases Rac1 and Rac2 in an electron generator system that uses NADH or NADPH as substratum. Once activated, the enzymatic complex is responsible for the electron inflow to the molecular oxygen, yields superoxide anion. Thus, based on the literature and results previously obtained by our group, this study analyzed the protein and gene expression of the NAD(P)H-oxidase complex subunits respectively by immunolocalization and Westernblotting and rt-PCR, in the mouse trophoblast stimulated with PMA. Rt-PCR semiquantitative analyses showed increase expression of the subunits p22-phox, gp91-phox, p47-phox, p67-phox, p40-phox and Rac1 in PMA-treated in comparison with non treated 
ectoplacental cones. The expression of the subunits gp91-phox, p47-phox and p67-phox were confirmed by Western blotting and, like gene expression also increased in the presence of PMA. These subunits were mostly located in the trophoblast giant cell population, associated to the phagocytic process at the maternal-placental interface. Increased expression of such subunits may be related to an increase in the $\mathrm{NAD}(\mathrm{P}) \mathrm{H}-$ oxidase activity. To analyze this possibility and to determine the role played by $\mathrm{NAD}(\mathrm{P}) \mathrm{H}-$ oxidase activity in the reactive oxygen species produced by trophoblast cells, cellular assays were performed using the oxyethidium fluorescence, a product of dihydroethidium oxidation by superoxide anion. Thus, under PMA stimulus and antimycin A that blocks the mitochondrial $\mathrm{NAD}(\mathrm{P}) \mathrm{H}$-oxidase activity and, apocynin and allopurinol, respectively blocking the membrane $\mathrm{NAD}(\mathrm{P}) \mathrm{H}$-oxidase and xhantine oxidase and, still, using specific superoxide and hydrogen peroxide scavengers (superoxide dismutase enzyme and catalase) we showed the generation of reactive species of oxygen- $\mathrm{NAD}(\mathrm{P}) \mathrm{H}$-oxidase dependent by trophoblast cells, mostly when stimulated. These results come to add important information about the potential of the trophoblast in producing reactive species at the maternal-fetal interface and, open a new investigation interest on the NADPH-oxidase regulatory processes and its involvement in defense functions of the embryo in both healthy and pathological processes that can determine the failure of the gestation.

Key words: Trophoblast cells; phagocytosis; NAD(P)H-oxidase; superoxide anion; gp91phox; p67-phox 


\section{INTRODUÇÃO}

As células trofoblásticas, característica ímpar dos mamíferos, são fundamentais para o sucesso da gestação, sendo as mediadoras da íntima interação que se desenvolve entre o organismo materno e o embrião/feto durante toda a gestação.

Posicionadas estrategicamente entre a circulação materna e fetal., estas células envolvem completamente o embrião e são responsáveis, durante as fases iniciais do processo de implantação, pela sua ancoragem ao endométrio com o objetivo de alcançar os vasos maternos para a aquisição de nutrientes para o seu desenvolvimento.

Particularmente em animais que desenvolvem uma placenta do tipo hemocorial (sangue materno em contato direto com o cório), tais como em roedores e primatas, o trofoblasto torna-se caracteristicamente invasivo e fagocítico. A atividade fagocitária exibida pelo trofoblasto em roedores apresenta sua máxima de atividade durante o período de implantação e declina gradativamente, na medida em que a placenta se desenvolve e adquire outras funções vitais. Aparentemente a fagocitose facilita o processo de invasão

embrionária, está envolvida com a nutrição do embrião antes da formação da placenta e sem dúvida, participa da aquisição de espaço para o desenvolvimento embrionário e fetal (TACHI et al., 1970; BILLINGTON, 1971; WELSH e ENDERS, 1985, 1987; KATZ e ABRAHANSOHN, 1987; BEVILACQUA e ABRAHAMSOHN, 1988, 1989; KANAIAZUMA, 1994; AMARANTE, 1997).

Em condições especiais, mesmo após a maturação da placenta, no entanto, o processo de fagocitose pode ser reativado na presença de partículas estranhas na interface materno-fetal (AMARANTE et al., 2004). Neste contexto, acredita-se que a atividade fagocítica das células trofoblásticas está também relacionada à proteção do embrião/feto, na medida em que participa da remoção de microorganismos da interface materna, o que corrobora trabalhos anteriores, in vitro, que descreveram fagocitose de microorganismos por células trofoblásticas (SCHLESINGER e KOREN, 1975; PAVIA, 1983; DRAKE e RODGER, 1987; AMARANTE et al., 2004). Nos últimos 10 anos, também vêm sendo 
atribuídos a esta atividade celular papéis nos processos imunoregulatórios da gestação (GUILBERT et al., 1993).

A despeito do grande número de trabalhos recentes caracterizando muitos dos aspectos da biologia do trofoblasto, a atividade fagocitária destas células retém ainda grandes controvérsias.

Em células de defesa também denominadas de fagócitos profissionais tais como macrófagos e neutrófilos, este processo tem sido exaustivamente estudado nas últimas décadas. Nestas células, a ativação da fagocitose está intimamente associada à aquisição de competência para o desempenho de funções tumoricidas, microbicidas ou citolíticas (LEWIS e MCGEE, 1992) resultantes da produção e liberação de espécies reativas de oxigênio.

As espécies reativas de oxigênio são moléculas dotadas de grande instabilidade e reatividade, comportando-se como receptores (oxidantes) ou doadores (redutores) de elétrons (HALLIWEL e GUTTERIDGE, 1991), representadas principalmente pelo ânion superóxido $\left(\mathrm{O}^{-}\right)$, peróxido de hidrogênio $\left(\mathrm{H}_{2} \mathrm{O}_{2}\right)$ e radical hidroxila $(\mathrm{OH} \cdot)$. Estas moléculas são formadas constantemente no organismo e, são convencionalmente consideradas tóxicas para o metabolismo celular quando extrapolam os limites fisiológicos da homeostase orgânica. No entanto, possuem um importante papel na sinalização e regulação funcional da célula e suas atividades fisiológicas, tais como: crescimento, divisão, transformação, apoptose, envelhecimento celular e principalmente fagocitose (LI et al., 2002).

Estudos realizados anteriormente em nosso laboratório mostram que o trofoblasto mantém sua atividade fagocitária no período pós-implantação e apresenta características fagocíticas semelhantes à de macrófagos e neutrófilos (ALBIERI e BEVILACQUA, 1996; GAGIOTI et al., 1995, 1996, 2000; GOMES, 1998). Particularmente importante neste contexto foram os achados de Gagioti e et al. (1996) que mostraram que as células trofoblásticas apresentam sítios produtores de peróxido de hidrogênio na superfície celular, quando estas células eram submetidas à estimulação com agentes conhecidamente ativadores da fagocitose em macrófagos.

Desta forma, para contribuir com a compreensão do papel do trofoblasto na fisiologia da gestação, particularmente no que tange a seu papel como barreira e defesa 
embrionária/fetal., este estudo teve como objetivo investigar a expressão dos componentes do complexo enzimático $\mathrm{NAD}(\mathrm{P}) \mathrm{H}$-oxidase, uma das principais fontes de produção de espécies reativas de oxigênio nos fagócitos profissionais, nas células trofoblásticas de camundongo. 


\section{CONCLUSÃO}

Os resultados nos permitiram concluir que:

1. As células trofoblásticas provenientes de cones ectoplacentários na fase de pósimplantação expressam as subunidades do complexo NAD $(\mathrm{P}) \mathrm{H}$-oxidase de membrana p22phox, gp91-phox, p47-phox, p40-phox, p67-phox e Rac1 previamente descritas em fagócitos e envolvidas com a atividade fagocitária destas células.

2. Ocorre modulação da expressão das subunidades do complexo enzimático $\mathrm{NAD}(\mathrm{P}) \mathrm{H}-$ oxidase sob o estímulo com PMA, agente capaz de fosforilar a subunidade p47-phox e ativar esta enzima em fagócitos profissionais.

3. Nossos ensaios experimentais indicam que as células trofoblásticas são capazes de gerar espécies reativas de oxigênio dependente da atividade do complexo NAD(P)H-oxidase de membrana de baixa intensidade quando não estimuladas e de forma muito mais intensa quando estimuladas pelo PMA.

As características de expressão e atividade do complexo enzimático NAD(P)H-oxidase de membrana encontradas neste estudo sugerem que esta enzima é semelhante a encontrada em outros fagócitos e, desta forma possa talvez estar também envolvida com processos de defesa da interface materno-fetal. 


\section{REFERÊNCIA *}

ALBIERI, A.; BEVILAQUA, E. Induction of erythrophagocytosis activity in cultured mouse trophoblast cells by phorbol myristate acetate by the and all-trans-retinal. Placenta, v. 17, p. 507-512, 1996.

ALBIERI, A.; HOSHIDA, M.S.; GAGIOTI, S.M.; LEANZA, E.C.; ABRAHAMSOHN, I.; CROY, A.; ASHKAR, A.A.; BEVILACQUA, E. Interferon-gamma alters the phagocytic activity of the mouse trophoblast. Reprod. Biol. Endocrinol., v. 10, p. 3-34, 2005.

ALDRIDGE, R.E.; CHAN, T.; VAN DALEN, C.J.; SENTHILMOHAN, R.; WINN, M.; VENGE, P.; TOWN, G.I.; KETTLE, A.J. Eosinophil peroxidase produces hypobromous acid in the airways of stable asthmatics. Free Radic. Biol. Med., v. 33, p. 847-856, 2002.

AMARANTE, A.M. Estudo imunocitoquímico das catepsinas D e B em células trofoblásticas gigantes de camundongos. 97p. Dissertação (Mestrado em Biologia Celular) - Instituto de Ciências Biológicas, Universidade de Campinas, Campinas, 1997.

AMARANTE-PAFFARO, A.; QUEIROZ, G.S.; CORREA, S.T.; SPIRA, B.; BEVILACQUA, E. Phagocytosis as a potential mechanism for microbial defense of mouse placental trofoblast cells. Reproduction, v.128, p.207-218, 2004.

AMARANTE-PAFFARO, A.; GONÇALVES, C.R.; BEVILACQUA, E. Cultura de Células Trofoblásticas de Roedores. Como cultivar células. Rio de Janeiro: Guanabara Koogan, 2005. p. 62-74.

BABIOR, B.M. The Activity of Leukocyte NADPH Oxidase: Regulation by $447^{\text {PHOX }}$ Cysteine and Serine Residues. Antioxid. Redox. Signal., v. 4, p. 35-38, 2002.

BABIOR, B.M. NADPH oxidase. Curr. Opin. Immunol., v. 16, p. 42-47, 2004.

BAUDRY, N.; LAEMMEL, E.; VICAUT, E. In vivo reactive oxygen species production induced by ischemia in muscle arterioles of mice: Involvement of xanthime oxidase and mitochondria. Am. J. Physiol. Heart Circ. Physiol., v. 294, n.2, p. H821-828, 2008.

BEVILACQUA, E.; ABRAHAMSOHN, P.A. Ultrastructure of trophoblast giant cell transformation during the invasive stage of implantation of the mouse embryo. $\mathbf{J}$. Morphol., v. 198, p. 341-345, 1988.

BEVILACQUA, E.; ABRAHAMSOHN, P.A. Trophoblast invasion during implantation of the mouse embryo. Arch. Biol. Med. Exp., v. 22, p.107-118, 1989.

\footnotetext{
${ }^{*}$ De acordo com: ASSOCIAÇÃO BRASILEIRA DE NORMAS TÉCNICAS. NBR 6023: Informação e documentação: referências: elaboração. Rio de Janeiro, 2002.
} 
BEVILACQUA, E.; FARIA, M.R.; ABRAHAMSOHN, P.A. Growth of mouse ectoplacental cone cells in subcutaneous tissues. Development of placental-like cells. Am. J. Anat., v. 192, p. 382-399, 1991.

BEVILACQUA, E.; ABRAHAMSOHN, P.A. Invasiveness of mouse trophoblastic cells in connective tissue. Acta Anat., v. 150, p. 246-252, 1994.

BEVILACQUA, E.; BUSSOLATI, O.; DALL'ASTA, V.; GACCIOLI, F.; SALA, R.; GAZZOLA, G.C.; FRANCHI-GAZZOLA, R. SNAT2 silencing prevents the osmotic induction of transport system $\mathrm{A}$ and hinders cell recovery from hypertonic stress. FEBS Lett., v. 20, p. 3376-3380, 2006.

BILlingtON, W.D. Biology of trophoblast. Adv. Reprod. Physiol., v. 5, p.27-66, 1971.

BILLINGTON, W.D. Immunological aspects of normal and abnormal pregnancy. Eur. J. Obstet. Gynecol. Reprod. Biol., v. 5, p. 147-154, 1975.

BINDOKAS, V.P.; JORDAN, J.; LEE, C.C.; MILLER, R.J. Superoxide production in rat hippocampal neurons: selective imaging with hydroethidine. J. Neurosci., v. 16, p. 324$336,1996$.

BOYD, J. D.; HAMILTON, W. J. Cleavage, early development and implantation of the egg. In: PARKERS, A. S. (Ed.). Marshall's Physiology of Reproduction. London : Longmans, 1952. p.1-126.

BRADFORD, L.W. A rapid and sensitive method for the quantitation of microgram quantities of protein utilizing the principle of protein-dye binding. Anal. Biochem., v. 72, p. 248-54, 1976.

BRIGS, R.T.; KARNOVSKY, M.L.; KARNOVSKY, M.J. Cytochemical demonstration of hydrogen peroxide in polymorphonuclear leukocyte phagosomes. J. Cell. Biol., v. 64, p. 254-60, 1975.

BUETLER, T. M.; KRAUSKOPF, A.; RUEGG, U. T. Role of superoxide as a signaling molecule. News Physiol. Sci., v. 19, p. 120-23, 2004.

CHAMSEDDINE, A.H.; MILLER, F.J. Vascular signaling by free radicals gp91phox contributes to NADPH oxidase activity in aortic fibroblasts but not smooth muscle cells. Am. J. Physiol. Heart. Circ. Physiol. v. 285, p. H2284-H2289, 2003. 
CHOMICZYNSKI, P.; SACCHI, N. Single-step method of RNA isolation by acid guanidinium thiocyanate phenol chloroform extraction. Anal. Biochem., v. 162, p. 156$159,1987$.

COOP, A.J. Interation between inner cell mass and trophectoderm of the mouse blastocyst (the fate of the polar trophectoderm). J. Embryok. Exp. Mophol., v. 5, p. 109-120, 1979.

CROSS, J.C. Genetic insights into trophoblast differentiation and placenta morphogenesis. Sem. Cell. Dev. Biol., v. 11, p. 105-113, 2000.

DAVIES, J.; HESSELDAHL, H. Comparative embryology of mammalian blastocyst. In: BLANDAU, R. J. The biology of blastocyst. Chicago: University Chicago Press, 1971.

DECOURSEY, T.E.; LIGETI, E. Regulation and termination of NADPH oxidase activity. Cell. Mol. Life Sci., v. 62 p. 2173-2193, 2005.

DELEO, F.; QUINN, M. T. Assembly of the phagocyte NADPH oxidase: molecular interaction of oxidase proteins. J. Leuk. Biol. v. 60, p. 677-91, 1996.

DICKSON, A. D. Cytoplasmatic changes during the giant cell transformation of blastocysts from normal and ovarectomized mice. J. Anat., v. 105, p.371-380, 1969.

DRAKE, B. L.; RODGER, J.C. Phagocytic properties of cultured murine trophoblast. Placenta, v.8, p. 129-134, 1987.

DUSI, S.; DELLA, B. V.; GRZESKOWIAK, M.; ROSSI, F. Relationship between phosphorylation and translocation to the plasma membrane of p47phox and p67phox and activation of the NADPH oxidase in normal and $\mathrm{Ca}(2+)$-depleted human neutrophils. Biochem. J., v. 15, p. 173-178, 1993.

ELLSON, C. D.; GOBERT-GOSSE, S.; ANDERSON, K. E.; DAVIDSON, K.; ERDJUMENT-BROMAGE, H.; TEMPST, P.; THURING, J. W.; COOPER, M. A.; LIM, Z. Y.; HOLMES, A. B.; GAFFNEY, P. R.; COADWELL, J.; CHILVERS, E. R.; HAWKINS, P. T.; STEPHENS, L. R. Ptdlins(3)P regulates the neutrophil oxidase complex by biding to the PX domain of p40(phox). Nat. Cell. Biol., v. 3, n. 7, p. 679-82, 2001.

ENDERS, A. C.; SCHLAFKE, S. Comparative aspects of blastocyst-endometrial interaction at implantation in maternal recognition of pregnancy. Exc. Med., v. 64, p. 3-32, 1979.

FUKUI, T.; ISHIZAKA, N.; RAJAGOPALAN, S.; LAURSEN, J.B.; CAPERS, Q. $4^{\mathrm{TH}}$; TAYLOR, W.R.; HARRISON, D.G; DE LEON, H.; WILCOX, J.N.; GRIENDLING, K.K. p22phox mRNA expression and NADPH oxidase activity are increased in aortas from hypertensive rats. Circ. Res. v. 80, p. 45-51, 1997. 
FRUEHAUF, J.P. Meyskens reactive oxygen species: a breath of life or death? Clin. Cancer. Res., v.13, p. 789-794, 2007.

GAGIOTI, S.M.; COLEPICOLO, P.; BEVILACQUA, E. Post-implantation mouse embryo has the capability to generate and release reactive oxygen species. Reprod. Fertil. Dev., v. 7, p. 1111-1116, 1995.

GAGIOTI, S.M.; COLEPICOLO, P.; BEVILACQUA, E. Reactive oxygen species and the phagocytosis process of hemocorial trophoblast. J. Braz. Assoc. Adv., v. 48, p. 37-42, 1996.

GAGIOTI, S.M.; SCAVONE, C.; BEVILACQUA, E. Participation of the mouse implantying trophoblast in nitric oxide production during pregnancy. Biol. Reprod. v. 62, p.260-268, 2000 .

GEORGIADES, P.; FERGUSON-SMITH, A.C.; BURTON, G.J. Comparative developmental anatomy of the murine and human definitive placentae. Placenta, v.23, p. 319, 2002.

GILLBERT, M.; DEHRY, Z.; TERRIER, M.; EL BENNA, J.; LEDERER, F. Another biological effect of tosylphenylalanylchloromethane (TPCK): it prevents p47 phox phosphorylation and translocation upon neutrophil stimulation. Biochem. J. v.386, p.549556, 2005.

GOMES, S.Z. Deslocamento e morte de células normais por células trofoblásticas. 1998. 88 f. Dissertação (Mestrado em Biologia Celular) - Instituto de Ciências Biomédicas da Universidade de São Paulo, São Paulo, 1998.

GONÇALVES, C.R.; ANTONINI, S.; VIANA-MORGANTE， A.M.; MACHADOSANTELLI, G.M.; BEVILACQUA, E Developmental changes in the ploidy of mouse implanting trophoblast cells in vitro. Histochem. Cell. Biol., v. 119, p. 189-198, 2003.

GORLACH, A.; BRANDES, R.P.; NGUYEN. K.; AMIDE, M.; DEHGHANI, F.; BUSSE, R. A gp91-phox containing NADPH oxidase selectively expressed in endothelial cells is a major source of oxygen radical generation in the arterial wall. Circ. Res., v. 87, p. 26-32, 2000.

GRAHAM, C.H.; LALA, P.K. Mechanism of control of trophoblast invasion in situ. $\underline{\mathbf{J}}$ Cell. Physiol., v. 48, n. 2, p. 228-34, 1991. 
GRIENDLING, K.K.; SORESCU, D.; LASSEGUE, B.; USHIO-FUKAI, M. Modulation of protein kinase activity and gene expression by reactive oxygen species and their role in vascular physiology and pathophysiology. Arterioscler. Thromb. Vasc. Biol., v. 20, p. 2175-83, 2000.

GROEMPING, Y.; LAPOUGE, K.; SMERDON, S.J.; RITTINGER, K. Molecular basis of phosphorylation-induced activation of the NADPH oxidase. Cell. v. 113, p. 343-355, 2003.

GUILBERT, L.; ROBERTSON, S.A.; WEGMANN, T.G. The trophoblast as an integral component of macrophage-cytokine network. Immunol. Cell. Biol., v. 71, p. 49-57, 1993.

HALLIWELL, B.; GUTTERIDGE, J.M.C. Free Radicals in Biology and Medicine. Oxford: Clarendon Press, 1991. p. 372-388.

HEYWORTH, P. G.; CROSS, A. R.; CURNUTTE, J. T. Chronic granulomatous disease. Curr. Opin. Immunol., v. 15, n. 5, p. 578-584, 2003.

HOFFMAN, L.H.; WOODING, F.B.P. Giant and binucleate cells of mammals. J. Exp. Zool., v.266, p 559-577, 1993.

HORDIJK, P. L. Regulation of NADPH oxidases: the role of Rac proteins. Circ. Res., v. 98, n. 4, p. 453-462, 2006.

JONES, S.A.; WOOD, J.D.; COFFEY, M.J.; JONES, O.T.G. The functional expression of p47-phox and p67-phox may contribute to the generation of superoxide by an NADPH oxidase-like system in human fibroblasts. Febs Letters, v. 355, p. 178-182, 1994.

KANAI-AZUMA, M.; KANAI Y.; KUROHMARU, M.; TACHI, C.; YAZAKI, K.; HAYASHI, Y. Giant cell transformation of trophoblast cells in mice. Endocrine J., v.41, p. S33-41, 1994. Suppl.

KATZ, S.; ABRAHAMSOHN, P.A. Involution of the antimesometrial deciduas in the mouse (an ultrastructural study). Anat. Embryol., v. 176, p. 251-258, 1987.

KAUFMANN, M.H. The origin, properties and fate of trophoblast in the mouse: In: LOKE, Y.W.; WHYTE, A. (Ed.). Biology of Trophoblast. Amsterdam: Elsevier, 1983. p.401-467.

KIM, J.S.; DIEBOLD, B.A.; KIM, J.I.; KIM, J.; LEE, J.Y.; PARK, J.B. Rho is involved in superoxide formation during phagocytosis of opsonized zymosans. J. Biol. Chem., v. 14, p. 21589-21597, 2004. 
KIM, C.; DINAUER, M.C. Rac2 is an essential regulator of neutrophil nicotinamide adenine dinucleotide phosphate oxidase activation in response to specific signaling pathways. J. Immunol. v.166, p. 1223-1232, 2001.

KOHEN, R.; NYSKA, A. Oxidation of biological systems: oxidative stress phenomena, antioxidants, redox reactions, and methods for their quantification. Toxicol. Pathol., v. 30, n. 6, p. $620-50,2002$.

KRIJNEN, P.A.; MEISCHL, C.; HACK, C.E.; MEIJER, C.J.; VISSER, C.A.; ROOS, D.; NIESSEN, H.W. Increased Nox2 expression in human cardiomyocytes after acute myocardial infarction. J. Clin. Pathol., v.56, p. 194-199, 2003.

KURIBAYASHI, F.; NUNOI, H.; WAKAMATSU, K.; TSUNAWAKI, S.; SATO, K.; ITO, T.; SUMIMOTO, H. The adaptor protein $\mathrm{p} 40$ (phox) as a positive regulator of the superoxide-producing phagocyte oxidase. EMBO J., v. 21, n. 23, p. 6312-6320, 2002.

LAPOUGE, K.; SMITH, S. J.; GROEMPING, Y.; RITTINGER, K. Architecture of the p40-p47-p67phox complex in the resting state of the NADPH oxidase. A central role for p67phox. J. Biol. Chem., v. 277, n. 12, p. 10121-10128, 2002.

LEWIS, C.; McGEE, J.O.D. The macrophage. Oxford: IRL Press, 1992. p. 3-114.

LI, J.M.; MULLEN, A.M.; YUN, S.; WIENTJES, F.; BROUNS, G.Y.; THRASHER, A.J.; SHAH, A.J. Essential role of the NADPH oxidase subunit $\mathrm{p} 47^{\text {phox }}$ in endothelial cell superoxide production in response to phorbol ester and tumor necrosis factor-alpha. Circ. Res., v. 90, p. 143-150, 2002.

LI, J.M.; SHAH, A.M. Differential NADPH- versus NADH-dependent superoxide production by phagocyte-type endothelial cell NADPH oxidase. Cardiovasc. Res., v. 52, p. 477-486, 2001.

LI, J.M.; SHAH, A.M. Intracellular localization and preassembly of the NADPH oxidase complex in cultured endothelial cells. J. Biol. Chem., v. 277, p. 19952-19960, 2002.

LI, N.; YI, F.X.; SPURRIER, J.L.; BOBROWITZ, C.A.; ZOU, A.P. Production of superoxide through NADH oxidase in thick ascending limb of Henle's loop in rat kidney. Am. J. Physiol. Renal. Physiol., v. 6, p. 1111-1119, 2002.

LYLE, A. N.; GRIENDLING, K. K. Modulation of vascular smooth muscle signaling by reactive oxygen species. Physiology, v. 21, p. 269-80, 2006. 
MANES, C. Human placental NADPH solubilization and properties. Placenta, v. 22, p. $58-63,2001$.

MANTOVANI, B. Phagocytosis of immune complexes mediated by $\operatorname{IgM}$ and $\mathrm{C} 3$ receptors by macrophages from mice treated with glycogen. J. Immunol., v. 126, n. 1, p. 127-30, 1981.

MATSUBARA, S.; SATO, I. Enzyme histochemically detectable NAD(P)H oxidase in human placental trophoblasts: normal., preeclamptic, and fetal growth restrictioncomplicated pregnancy. Histochem. Cell. Biol., v. 116, p. 1-7, 2001 a.

MATSUBARA, S.; SATO, I. NAD(P)H oxidase in human fetal membrane chorion laeve trophoblasts with or without chorioamnionitis: ultrastructural enzyme histochemical study.

Mol. Hum. Reprod., v. 7, p. 779-785, 2001 b.

MCNALLY, J.S.; DAVIS, M.E.; GIDDENS, D.P.; SAHA, A.; HWANG, J.;DIKALOV, S.; JO, H.;HARRISON, D.G. Role of xanthine oxidoreductase and NAD(P)H oxidase in endothelial superoxide production in response to oscillatory shear stress. Am. J. Physiol. Heart Circ. Physiol., v. 285, p. H2290-2297, 2003.

MEHROTRA, P.K. Ultrastructure of mouse ectoplacental cone cells. Biol. Struct. Morphol., v. 1, p. 63-68, 1988.

MEYER, J.W.; SCHMITT, M.E. A central role for the endothelial NADPH oxidase in atherosclerosis. FEBS Lett., v. 472, p. 1-4, 2000.

MOHAZZAB, K. M.; WOLIN, M. S. Oxidant signallyng and vascular oxygen sensing. Role of $\mathrm{H} 2 \mathrm{O} 2$ in responses of the bovine pulmonary artery to changes in PO2. Adv. Exp. Med. Biol., v. 475, p. 249-58, 2000.

MOHAZZAB, K.M.; KAMINSKI, P.M.; WOLIN, M.S. NADH oxidoreductase is a major source of superoxide anion in bovine coronary artery endothelium. Am. J. Physiol., v. 266, p. H2568-2572, 1994.

MOSSMAN, H. W. Carnivora. In: Vertebrate fetal membranes. New Jersey: Rutgers University Press, 1987. p. 250-62.

MOSSMAN, H.W. Comparative morphogenesis of the fetal membranes and accessory uterine structures. Contr. Embryol. Inst., v. 26, p. 133-246, 1937.

MYATT, L.; CUI, X. Oxidative stress in the placenta. Histochem. Cell. Biol., v. 122, p. 369-382, 2004. 
MYATT, L. Placental adaptive responses and fetal programming. J. Physiol., v. 572, p. 25-30, 2006. Pt 1.

NAUSSEF, W.M. Assembly of the phagocyte NADPH oxidase. Histochem. Cell. Biol., v. 122, p. 277-291, 2004.

NEWBURGER, P.E.; EZEKOWITZ, R.A.; WHITNEY, C.; WRIGHT, J.; ORKIN, S.H. Induction of phagocyte cytochrome $b$ heavy chain gene expression by interferon gamma. Proc. Natl. Acad. Sci., v. 85, p. 5215-5219, 1988.

NISHIDA, A.; KIMURA, H.; SUGIOKA, K.; NAKANO, M. The ability of granulocytes to generate superoxide anions and hypochlorite during phagocytosis: comparison of neonatal granulocytes with adult granulocytes. Biol. Neonate, v. 58, n. 3, p. 145-51, 1990.

PAVIA, C.S. Expression of the cell-mediated antimicrobial immunity by mouse trophoblast monolayers. J. Infect. Dis., v.147, p.8-32, 1983.

PEEL, S.; BULMER, D. Proliferation and differentiation of the trophoblast in the establishment of the rat chorio-allantoic placenta. J. Anat., v.124, p. 675-687, 1976.

QUINN, M. T.; AMMONS, M. C. B.; DELEO, F. The expanding role of NADPH oxidases in health and disease: no longer just an agent of death and destruction. Clin. Sci., v. 111, p. $1-20,2006$.

QUINN, M. T.; EVANS, T.; LOETTERLE, L. R.; JESAITIS, A. J.; BOKOCH, G. M. Translocation of Rac correlates with NADPH oxidase activation. Evidence for equimolar translocation of oxidase components. J. Biol. Chem., v. 268, n. 28, p. 20983-20987, 1993.

QUINN, M. T.; GAUSS, K. A. Structure and regulation of the neutrophil respiratory burst oxidase: comparison with nonphagocyte oxidases. J. Leuk. Biol. v. 76, p. 760-81, 2004.

RAIJMARKERS, M.T.; BURTON, G.J.; JAUNIAUX, E.; SEED, P.T.; PETERS, W.H.M.; STEEGERS, E.A.; POSTON, L. Placental NAD(P)H oxidase mediated superoxide generation in early pregnancy. Placenta, v. 27, p. 158-163, 2006.

RAO, P.V.; MADDALA, R.; JOHN, F.; ZIGLER JR, J.S. Expression of nonphagocytic NADPH oxidase system in the ocular lens. Mol. Vis., v. 10, p. 112-121, 2004.

REY, F.E.; LI, X.C.; CARRETERO, O.A.; GARRIN, J.T.; PAGANO, P.J. Perivasculas superoxide anion contributes to impairment of endothelium-dependent relaxation: role of gp91(phox). Circulation, v. 106, p. 2497-2502, 2002. 
ROBY, K.F.; SOARES, J.M. Trophoblast cell differentiation and organization: role of fetal and ovarian signals. Placenta, v. 14, p. 529-545, 1993.

ROTROSEN, D.; LETO, T. L. Phosphorylation of neutrophil 47-kDa cytosolic oxidase factor. Translocation to membrane is associated with distinct phosphorylation events. J. Biol. Chem., v. 265, n. 32, p. 19910-5, 1990.

SAMBROOK, J.; FRITSCH, E. F.; MANIATIS, T. Molecular cloning: A Laboratory Manual. New York: Cold Spring Harbor Laboratory Press, 1989.

SCHLESINGER, M.; KOREN, Z. Mouse trophoblast cells in tissue culture. Fertil. Steril., v. 18 , p. 95-101, 1975.

SEAL., U.S.; SINHA, A.A.; DOE, R.P. Placental iron transfer: relationship to placental anatomy and phylogeny of the mammals. Am. J. Anat., v. 134, p. 263-269, 1972.

SERRANO, F.; KOLLURI, N.S.; WIENTJES, F.B.; CARD, J.P.; KLANN, E. NADPH oxidase immunoreactivity in the mouse brain. Brain Res., v. 988, p. 193-198, 2003.

SHUKLA, R.; MEHROTRA, P. K.; MAITRA, S. C.; KAMBOJ, V. P. Ultrastructural morphology of ectoplacental cone trophoblasts of hamster embryos. Acta Anat., v. 142, n. 2, p. 105-10, 1991.

SNELL, G. D.; STEVENS, L. C. Early embryology. In: SNELL, G. D. (Ed.). Biology of the laboratory mouse. New York: McGraw Hill, 1966. p. 205-45.

SUMIMOTO, H.; UENO, N.; YAMASAKI, T.; TAURA, M.; TAKEVA, R. Molecular mechanism underlying activation of superoxide-producing NADPH oxidases: roles for their regulatory proteins. Jpn. J. Infect. Dis., v. 57, n. 5, p. S24-5, 2004.

SZOCS. K; LASSEGUE, B; SORESCU, D; HILENSKI, L.L. VALPPU, L; COUSE, T.L; WILCOX, J.N.; QUINN, M.T.; LAMBETH, J.D.; GRIENDLING, K.K. Upregulation of Nox-based NAD(P)H oxidases in restenosis after carotid injury. Arterioscler. Thromb. Vasc. Biol., v. 22, p. 21-27, 2002.

TACHI S.; TACHI C.; LINDNER G.R. Ultrastructural features of blastocysts attachment and trophoblastic invasion in the rat. J. Reprod. Fertil., v.21, p.37-56, 1970.

TAKEYA, R.; SUMIMOTO, H. Molecular mechanism for activation of superoxideproducing NADPH oxidases. Mol. Cell., v. 16, p. 271-277, 2003.

TAKEYA, R.; UENO, N.; SUMIMOTO, H. Regulation of superoxide-producing NADPH oxidase in nonphagocytic cells. Methods Enzymol., v. 406, p. 456-468, 2006. 
TAMTA, H.; KABRA, S.; MUKHOPADHYAY, A. K. Biochemical characterization of some pyrazolopyrimidine - based inhibitors of xanthine oxidase. Biochemistry, v. 71, p. S49-S51, 2006.

TANAKA, S.; KUNATH, T.; HADJANTONAKIS, A. K.; NAGY, A.; ROSSANT, J. Promotion of trophoblast stem cell proliferation by FGF4. Science, v. 282, p. 2072-2075, 1998.

VALKO, M.; LEIBFRITZ, D.; MONCOL, J.; CRONIN, M.T.; MAZUR, M.; TELSER, J. Free radical and antioxidants in normal physiological functions and human disease. Int. J. Biochem. Cell. Biol., v. 29, p. 44-84, 2007.

VEJRAZKA, M.; MICEK, R.; STIPEK, S. Apocynin inhibits NADPH oxidase in phagocytes but stimulates ROS production in non-phagocytic cells. Biochim. Biophys. Acta., v. 11, p. 143-147, 2005.

YU, L.; DELEO, F.R.; BIBERSTINE-KINKADE, K.J.; RENNEE, J.; NAUSEEF, W.M.; DINAUER, M.C. J. Biol. Chem. v. 274, p. 4364-4369, 1999.

WELSH, A.O.; ENDERS, A.C. Light and electron microscopic examination of the mature decidual cells of the rat with emphasis on the antimesometrial deciduas and its degeneration. Am. J. Anat., v.172, p. 1-30, 1985.

WELSH, A.O.; ENDERS, A.C. Trophoblast-decidual cell interaction and establishment of maternal blood circulation in the parietal yolk sac placenta of the rat. Anat. Rec., v.217, p.213-219, 1987.

WIENTJES, F. B.; SEGAL, A. W. NADPH oxidase and respiratory burst. Cell. Biology., v.6, p. 357-65, 1995.

WOLLIN, M.S. Interactions of oxidants with vascular signaling systems. Arterioscler. Thromb. Vasc. Biol., v. 20, p. 1430-1442, 2000. 